\title{
Advancing patient-centered care through transformative educational leadership: a critical review of health care professional preparation for patient-centered care
}

\author{
This article was published in the following Dove Press journal: \\ Journal of Healthcare Leadership \\ 12 July 2013 \\ Number of times this article has been viewed
}

\author{
Martine C Lévesque ${ }^{1,2}$ \\ Richard Bruce Hovey ${ }^{2,3}$ \\ Christophe Bedos 2,4 \\ 'Faculté de médecine, Université de \\ Montréal, Montréal, QC, Canada; \\ ${ }^{2}$ Division of Oral Health and Society, \\ Faculty of Dentistry, McGill University, \\ Montreal, QC, Canada; ${ }^{3}$ Faculty \\ of Medicine, University of Calgary, \\ Calgary, AB, Canada; ${ }^{4}$ Département \\ de médecine sociale et préventive, \\ Faculté de médicine, Université de \\ Montréal, Montréal, QC, Canada
}

Correspondence: Martine C Lévesque McGill Faculty of Dentistry, Oral Health and Society, 3550 University St., Montreal, QC, H3A 2A7, Canada

$\mathrm{Tel}+\mathrm{I} 5 \mathrm{I} 45255176$

Fax + I 5143987220

Email martine.levesque2@mail.mcgill.ca
Abstract: Following a historical brief on the development of patient-centered care (PCC), we discuss PCC's value and role in counterbalancing the evidence-based movement in health care. We in turn make a case for a philosophical shift in thinking about the PCC concept, one based on a consideration for how knowledge is produced, used, and valued within care provision processes. A "shared epistemology" foundation is presented, defined, and promoted as essential to the authentic and ethical realization of "shared decision making" between patient and health care provider, and, more generally, of PCC. In accordance with these views, this article critically reviews the literature on health care professional education for the development of PCC. We uncover the disturbing ways in which education frequently undermines the development of patient centeredness, despite curricular emphasis on professionalism and ethical PCC. We also establish the need to raise awareness of how dominant approaches to evaluating student or practitioner performance often fail to reinforce or promote patient centeredness. Finally, we identify successful and inspiring cases of teaching and learning experiences that have achieved perspective transformation on PCC and on new ways of providing care. The pertinence of adopting the theoretical foundations of adult transformative learning is argued, and a call to action is proposed to the leadership of health professional educators across all disciplines.

Keywords: patient-centered care, health professional education, transformative learning

\section{Introduction}

\section{Some PCC history}

The intellectual pedigree of patient-centered care (PCC) may be traced back to the 1970s. Inspired by the human rights activism movement in the USA, health researchers of that era pioneered studies on patients' perceptions of their health and their satisfaction with care. ${ }^{1}$ They also explored the knowledge and attitudes underpinning physicians' communication and listening skills. ${ }^{1}$

In the early 1990s, the advent of the "evidence-based movement" (EBM) in medicine was equally associated with an increase in concern with patient involvement in their health care. Evidence-based clinical decision making, founded on increasingly higher levels of statistical abstraction, was considered to risk distancing the health professional from the subjective illness experience. ${ }^{2}$ Given its consideration for the patient's unique history, needs, expectations, and context, PCC offered a promising counterbalance. . $^{3,4}$ submit your manuscript | www.dovepress.com
Dovepress

http://dx.doi.org// 0.2147/JHL.S30889 
The epidemiological shift from acute to predominantly chronic health care concerns in high-income societies has also contributed to the PCC movement because of the longitudinal and multidimensional nature of services involved. ${ }^{5}$ With growing health consumerism, and knowledge and patient empowerment associated with the use of the internet, the PCC movement will undoubtedly continue to expand. Patients and families want to be provided the opportunity to be respected partners in their care and meaningfully involved in decision making about their health. ${ }^{6}$

\section{The value of $P C C$}

More recently, PCC has been emphasized within trends that focus on meeting the health care needs of specific patient populations. PCC is considered to be at the core of cultural competency $^{7}$ and foundational to humanistic care delivery to people experiencing socioeconomic disadvantage. ${ }^{8}$ Indeed, a consideration for the impact of social, interpersonal, societal, and ecological health determinants is integral to PCC. ${ }^{9}$ The value and necessity of PCC has also been formally recognized in the USA, as evidenced by its inclusion among the top six competency areas that health care systems must strive to improve. ${ }^{10}$

Many studies have linked PCC to specific health outcomes and to service utilization. ${ }^{11}$ The more patients perceive their family physicians to be centered on them, the greater their recovery and mental health. ${ }^{12}$ Levels of post-encounter discomfort, concern, diagnostic testing, and referrals are also lower with greater perceived patient centeredness. ${ }^{12} \mathrm{PCC}$ has also been associated with reduced heart failure and asthma emergency room readmissions. ${ }^{13,14}$ Finally, inquiry into patients' and families' experiences of preventable medical errors have accentuated the significance of listening to and understanding patients, as well as the sometimes horrific consequences of failing to do so. ${ }^{15}$

\section{On defining PCC}

Despite an abundance of literature pertaining to PCC, there is limited consensus as to what exactly it consists of. ${ }^{16,17}$ Also, definitions frequently differ in the degree to which they attend to systemic/organizational aspects in comparison with direct professional health care provision. ${ }^{17,18}$ There is nonetheless convergence among authors regarding core dimensions of the concept when PCC is considered from the angle of patient-health professional interaction. One of our aims is to add to the PCC conversation by providing insight into the need for a transformation of perspective on PCC itself, so that health care professionals, policy makers, and others fully adopt a patient-centered approach. We argue, moreover, that most current PCC models, clinical or institutional, will be rendered ineffective unless this transformation in perspective takes place.

The necessity of perspective transformation is seen through the clinical model of Stewart et $\mathrm{al}^{2}{ }^{2}$ where PCC consists of six interactive components: (1) "exploring both the disease and the illness experience" (eg, patients' feelings, ideas, expectations); (2) "understanding the whole person" (eg, social context, life history, developmental stage); (3) "finding common ground" (ie, on problems, priorities, goals, and roles); (4) "incorporating prevention and health promotion"; (5) "enhancing the patient-doctor relationship" (eg, compassion, healing, self-awareness); and (6) "being realistic" (as to resources and time constraints). This model addresses the content of PCC but does not fully address the difficulty health care providers face in actually adopting these PCC-enhancing behaviors. Achieving this requires transformation of an acculturated perspective and the realization that PPC is, at its heart, an ethical encounter with the patient as a person.

Authentic and ethical PCC marks a paradigmatic affront to the practice of medicine and to that of many other health care professions. With its emphasis on a hierarchical system of proofs, the dominant EBM in health is largely founded on positivism. This term refers to a philosophy of science that views logic and mathematical treatment of information as the exclusive source of authoritative knowledge. Positivism, in health research, privileges specific methodologies over others and dictates what constitutes evidence and what does not. Knowledge produced in this manner is founded on a positivist "epistemology" or "way of knowing" that implies objectivity and detachment. ${ }^{19}$ This perspective constrains our viewpoint on knowledge production and clashes with the essence of patient centeredness when clinicians rely too heavily on it. In the absence of alternative views on knowledge and its legitimization, positivistic perspectives will tend to dominate and undermine the actualization of PCC.

The dynamic, process-based, and interactive nature of "finding common ground" and "enhancing the patientdoctor relationship" necessarily call for a shift in thinking about knowledge. This shift involves reassessing the value attributed to various sources and forms of knowledge and how these can be accessed. It also involves reconsidering how power should be distributed between patient and health care provider. Authentic PCC means that the patient's voice is heard loudly and clearly, not as an adjunct to a professional initiative, but as a knowledgeable other and 
partner with experiences capable of informing health care practices. ${ }^{6}$

When care is provided within a collaborative approach, the knowledge that guides treatment or prevention emerges in a space shared and actively negotiated by both parties. In other words, true PCC does not belong to either the health care provider or to the patient/family. Rather, PCC coexists between them and requires that knowledge be co-created. This manner of producing knowledge - greater than the sum of each party's knowledge taken separately - we refer to as a "shared epistemology." Neither positivistic nor entirely subjective, a shared epistemology is a joint venture, allowing patients and families to be active and meaningful partners in their care. Working through a sharing of epistemologies indeed enables the patient and practitioner to find common ground and, as it were, to bridge misunderstandings.

\section{Review questions and approach}

Guided by our philosophical stance, we reviewed the literature on PCC with the following broad questions in mind: How are we preparing health professionals for the provision of authentic and ethical PCC? How are we currently developing in students and practitioners an appreciation and capacity for shared epistemologies? What are the issues or barriers encountered? What educational approaches or strategies show promise?

We reviewed the literature generated through Medline and CINAHL databases by using the following keywords: education, curriculum, and patient-centered care. We purposefully did not search the literature on "person-centered care," a related concept, in order to maintain our focus on educational interventions that are mainstream in medicine, dentistry and in other health professions. Given the high volume of literature generated, we restricted our search to the mid-1990s and later, and to the English language. We also queried the results of this search with the keywords "transformative learning" in line with our concern with perspective transformation on PCC. Additional papers or texts were reviewed to address emergent issues or to deepen our understanding when pertinent.

\section{Educating health professionals to deliver PCC: a critical review}

Clearly, there is wide variability as to how and when PCC is addressed in various schools of medicine and in other health professions. Frequently, it is associated with communication skills training. ${ }^{20-24}$ PCC training is also described in terms of particular strategies, such as the use of standardized or simulated patients. ${ }^{25-28}$ Case-based seminars or problem-based learning are equally mentioned, ${ }^{29,30}$ as are eclectic training approaches that integrate lectures, role-play, group discussion, and patient encounters. ${ }^{31,32}$ Education on PCC often takes place within preclinical community-based or service-learning initiatives, ${ }^{33-36}$ or within clerkship or clinical training placements. ${ }^{9,37-42}$ Finally, several continuing education initiatives are described across a wide variety of professional fields, ranging from brief workshops to elaborate interdisciplinary training programs or extended action research projects. ${ }^{43-48}$

It is outside the interests of this article to perform criteriabased comparisons between the above-cited educational initiatives. We made a case earlier for the need to foster in practitioners and students a reconceptualization of PCC itself. This involves consideration - on their part and on that of educators - for the difference between content (PCC models, tools, best practices) and context/process (how health care providers actually behave with patients). It also entails our attendance to how knowledge is produced and used within the process of patient care. We reviewed the literature in accordance with these views. In doing so, we discovered the disturbing ways in which education frequently undermines the development of patient centeredness, despite curricular emphasis on professionalism and ethical patient-centered practice. We also uncovered the need to raise awareness of how dominant approaches to evaluating student or practitioner performance often fail to reinforce or promote patient centeredness. Finally, we were able to identify successful and inspiring cases of teaching and learning experiences achieving perspective transformation on PCC and new ways of providing care.

We describe the above-identified issues and challenges as well as the promising avenues for advancing PCC education in the following sections: PCC attitudes in health care students and practitioners; PCC measurement issues; and dimensions of promising approaches.

\section{PCC attitudes in health care students and practitioners}

Several studies have revealed that medical students' attitudes toward PCC, much as is the case with their levels of empathy ${ }^{49}$ tend to decline throughout their training and more markedly so over the course of their clinical clerkships. ${ }^{50-52}$ This is the case even when students have been exposed to extensive patient-centered communication skills training. ${ }^{22,53}$ Even though a few recent studies ${ }^{54,55}$ have not reproduced this finding, attitudes toward care remain a preoccupation: despite 
their stability over time in some cases, doctor-centered and cure-oriented (versus care-orientated) attitude levels have been shown to be high upon graduation. ${ }^{54,56}$

Attitude degradation during medical clerkship training has been associated with elements of the "hidden curriculum." ${ }^{57}$ This refers to the culture and "unwritten rules of medical education that exert a powerful influence on attitudes and behaviors. ${ }^{57}$ Hidden curricula may overpower formal content knowledge and contradict explicit messages on values and care. ${ }^{57}$ Similarly, the loss of patient centeredness is hypothesized to result from a clash between "ideal" PCC promoted in preclinical training and the "real" world of the hospital training environment. ${ }^{24}$ Third-year British medical students interviewed following their hospital placement expressed the inner conflict they experienced between their humanistic impulses and some of the learning demands placed on them. ${ }^{42}$ They equally observed condescension toward patient centeredness and described their awareness of how one can become desensitized. Lack of contact with - and feedback and support from - teachers were other issues raised. ${ }^{42}$ Constraints to providing PCC in the context of clerkship practice also include demanding work pace, fatigue, and need for self-preservation. . $2,53^{2}$

Hidden curricula also operate via role-modeled overreliance on technology and overemphasis on biomedical dimensions of care, as authors hypothesized in a Brazilian study. ${ }^{54}$ Although the Brazilian students did not show a decline in PCC attitudes when the entire cohort was considered, a "dip" in their scores occurred at the tenth semester, shortly after specialty medicine training was initiated. ${ }^{54}$ Biomedical focus of student evaluation at the expense of patient-centered practice indeed exerts a powerful influence on learners, despite the most well-intentioned curriculums. ${ }^{29}$

In essence, deterioration or loss of patient centeredness in medical students appears to result, to a good extent, from a devaluing of their own humanity in the struggle to respond to the pressures, context, and culture of medical training. Throughout this process, the student or trainee, and others, become diminished and replaced with the functional pragmatics of medicine. This may well constitute the first true distancing of the patient and health care practitioner as the professionals become distant to themselves; the health care providers learn to care from a dispassionate perspective, jeopardizing the efficacy of person centeredness, through an objective health professional stance.

PCC attitude issues are equally reflected in studies among practicing health care professionals. Both within acute care and long-term care settings, awareness of and modeling of
PCC on the part of nurse practitioners has been shown to be limited. ${ }^{58,59}$ Attitudinal barriers toward patient involvement in goal setting have also been documented among practicing physical and occupational therapists ${ }^{47}$ despite, in the case of the latter, a biopsychosocial foundational practice philosophy. Physical therapy is critiqued for the profession's predominantly biomedical orientation and the pragmatic nature of the profession's identity. ${ }^{60}$ Among practicing dentists, there is evidence of negative attitudes toward certain groups of patients themselves, affecting the desire for rapport and sometimes leading to the adoption of discriminatory practices that compromise access to care. ${ }^{61}$ Because it represents an important behavioral determinant, attitude is considered a pertinent proximal target for developing $\mathrm{PCC}^{22}$ and has been correlated with the perceived humanism of the medical encounter on the part of standardized patients. ${ }^{27}$

\section{PCC measurement issues}

Measuring patient centeredness is another critical issue that appears in the literature. Considered generally, measuring PCC is problematic owing to the complexity of the relational processes involved as well as the lack of theoretical clarity of the PCC concept. ${ }^{3}$ Many attempts at measurement have nonetheless been made. ${ }^{11}$ In their systematic review of the quantitative tools and approaches developed, Mead and Bower $^{3}$ describe and contrast self-report measures on the part of the doctor and external observation measures using rating scales or verbal behavior coding systems. The first category would present issues of social desirability and reliability over time. Trade-offs between reliability and validity also occur, when efforts to ensure a tool's reliability compromise its validity. In a recent study of communication skills training, the author questioned whether the trained students' increased ability to nuance their understanding of PCC was perhaps not captured by the self-report scales used. ${ }^{24}$

External observation methods, for their part, tend to evaluate instrumental (task-oriented) behaviors, mostly on the part of the professional. They have been critiqued for neglecting the emotional tone of the consultation ${ }^{3}$ and for emphasizing more easily measured skills to the detriment of other components. ${ }^{62}$ They also often present interpretation difficulties for the observer. Finally, none of the measures reviewed addressed the "doctor as person" dimension of the Mead and Bower PCC framework. ${ }^{3}$ This dimension attends to the subjective experience and reflexivity of the physician or professional. The authors discuss the idea that the "doctor as person" dimension requires idiographic systems of understanding and measurement capable of 
attending to subjectivities and contingencies. The importance of learning about these using a qualitative research approach is underscored.

One could say that the measurement of PCC in the educational literature is mainly characterized by "doctor centeredness." Paradoxically, it remains mostly disconnected from the professional's subjective experience and is dismissive of the "doctor as person." Currently, the most commonly used PCC measurement scale, the Patient-Practitioner Orientation Scale, addresses PCC beliefs and dispositions on the part of the practitioner. It curtails the actual "doing" of PCC and what this implies for the "doctor as person," despite the abundance of studies highlighting the latter's significance. ${ }^{9,25,42,53}$ In one evaluative study of a PCC educational approach, the difficulty most commonly cited by students, by far (66\%), was dealing with their own emotional response to the patient. ${ }^{9}$ The importance of emotional intelligence and of strengthening students' coping mechanisms for improving PCC has been emphasized in dental education as well. ${ }^{63}$

Developing these personal strengths in practitioners is indeed a key to ensuring their authentic presence during interactions with patients. Failure to bring forth the person behind the white coat into the patient encounter undermines such processes as "finding common ground" and "sharing power and decisions." These require a relinquishing of power on the part of the health practitioner in order to lessen the distance and promote a true encounter with the patient who, most likely, is not a health care professional. Yet, awareness of and attention to the power differential between patient and professional requires reflexivity and self-knowledge.

The above-described limits to PCC measurement are equally reflected in the discrepancies identified between measured professional behavior and patient perceptions of this behavior. Intriguingly, in Stewart et al's outcome study of physician-patient encounters, the patients' perception of patient centeredness was positively correlated with improved outcomes and decreased service utilization; ${ }^{12}$ no association was found between health or health care utilization outcomes and observed "patient-centered communication" scores based on audiotape analysis of physician behavior. Discrepancies of this magnitude highlight the complexities and contextualized nature of PCC.

Providing care from a shared epistemology framework is indeed highly complex. To a certain degree, PCC may be framed as a moving target. It is a joint venture and must subsume the ability on the part of the health care professional to detect and establish - with the patient - when dimensions of PCC (eg, discussing social context or patients' feelings) are desirable and achievable or not at a given moment. According to Stewart et al, ${ }^{2}$ highly patient-centered physicians show extremely variable lengths of patient consultations, whereas the opposite is true of less patient-centered physicians. This is the reflection of capacity for appreciation and respect of patient/carers' autonomy and desire for power. Shared epistemologies indeed represent a meta framework, not a set of behaviors but a conviction that the behaviors, techniques, and knowledge we teach should be at the service of the patient encounter.

\section{Dimensions of promising approaches}

The issues and concerns presented in this PCC review may appear quite discouraging as to the current status of health professional development of PCC. For instance, quantities of training activities taking place at the undergraduate level may be considered likely to be followed by the dreaded downward drift in attitudes as students undergo clinical training. Furthermore, positive outcomes of educational approaches measured in instrumental terms must spark off doubt as to whether or not they are truly depicting patient centeredness..$^{25,64}$

Yet, the literature does present some promising avenues for addressing process and contextual elements of PCC that correspond to potentially shared epistemologies. Many evaluative approaches integrate a qualitative dimension into their methodology. These provide insight into process and context, take into consideration the professional as person, and at times reveal reconceptualizations of patient centeredness itself. We discuss these promising directions in the following sections: focus on context and student centeredness; critical reflection on practice and self-awareness; and alternate ways of knowing. For the sake of clarity, we organize our text into these discrete sections. However, aspects of each at times overlap and several successful programs integrate two or more of these approaches.

\section{Focus on context and student centeredness}

There have been several attempts to purposively introduce new, or modify and study, clinical training contexts. ${ }^{38,39,41}$ These include curricular modifications that prolong students' stay within given clerkship sites (in lieu of rotations among large numbers of sites), ${ }^{39}$ that increase students' contact and interactions with given patients, ${ }^{38}$ or that implement completely new training environments. ${ }^{41}$ These educational approaches also most often integrate significant student mentorship and opportunities for discussion and meaningful reflection. The positive outcomes of these experiences are linked to 
interpersonal factors: sense of familiarity and relational continuity with staff, faculty, and patients; growing comfort and a sense of collegiality between mentor and mentee; and stronger ongoing peer support, in the case of Krupat et al's single-site third-year medical clerkship study. ${ }^{39}$

Howe's study of a newly implemented 8-week, community-based placement for fourth-year medical students revealed the fundamental role of person-centered learning. ${ }^{41}$ Study results indicated a shift toward whole-person perspectives and increased awareness of how relationships with patients influence consultations. Key learning mechanisms identified by students appeared to depend more on teachers' commitment to teaching than on formal teaching skills. Being valued as a person by staff and teachers "who mirrored the central nature of relationship between staff and patient by that between staff and student" were essential features identified. ${ }^{41}$ Another study contrasting third-year medical students' experiences of hospital-based training with general practice environments ${ }^{42}$ highlighted the sense of intimacy and relational advantages the latter provided. In the general practice settings, students commended their tutor's provision of detailed feedback and admitted it contributed to the development of their self-confidence; the general practice context also tended to put students more at ease for developing lines of questioning with their patients. ${ }^{42}$

The literature also describes the positive contributions of interprofessional training contexts to developing PCC. ${ }^{37,40} \mathrm{In}$ the Ruston and Tavabie ${ }^{37}$ PCC paramedic training case study, participants reported learning new ways of communicating with patients and improved ability to cope with uncertainty during decision making with patients; central learning mechanisms included exposure to general practitioners' patient-centered consultation skills and values, as well as the fact that their learning program was based on their assessed needs and individual learning styles. Interprofessional training environments may also contribute to learning in other ways. Physiotherapy students training within an interdisciplinary palliative care setting reported increased awareness and appreciation for holistic care. ${ }^{40}$ They emphasized the importance of professional diversity and interprofessional respect within the team as well as time allotted for interprofessional communication and interactions with patient/ family. Students equally underscored the value of ongoing support and appreciation on the part of the palliative care team in what was perceived as an emotionally challenging learning environment. Although interprofessional learning contexts uniquely provide students with access to multiple professional perspectives and roles, it is the quality of rapport between team members, patients, and trainees that is emphasized predominantly in the above studies.

In sum, successful context-based and student-centered clinical training innovations facilitate learning through the quality of interpersonal relationships among students, patients, trainers, and staff. Students participating in the cited studies stressed the importance of relational continuity, receiving emotional support, and feeling appreciated and recognized as individuals. These are all key features of PCC. The students equally underscored the contribution of positive modeling of values and ways of relating on the part of tutors, mentors, or supervisors. Interestingly, the positive results - in terms of increased awareness of, appreciation for, and comfort with patient centeredness - occurred at times in environments normally associated with empathy declines. This is cause for reflection and hopefulness.

\section{Critical reflection on practice and self-awareness}

In addition to providing relational support, facilitating students' and practitioners' critical reflection represents yet another key component of successful patient-centered educational endeavors. 9,31,43,65-67 A highly "mobile," versatile, and mostly low-tech teaching approach, reflection (eg, in small groups) can be integrated into clerkship training just as within undergraduate or continuing education courses. Critical reflection may relate to the content of role-plays, to the content of patient care taped recordings, or to content of direct observations on the part of clinical teachers. Smith ${ }^{66}$ adopted all three in a successful self-awareness training program with residents. Reflection may equally lean on the content of written material (eg, journals) and is frequently coupled with the educational innovations that we will discuss in the next section. In the following paragraphs, we focus on a few cases where critical reflection occupies a central role.

Continuing education studies often use recordings (ie, audio or video) of actual patient-professional interactions as a basis for reflection. ${ }^{43,67}$ In Lomborg et al's ${ }^{43}$ training on nursing practices with patients suffering from chronic obstructive pulmonary disease, reflective dialogues on videotaped interactions constituted the leading educational component. Through critical reflection on practice via videotape analysis of care provision, trainees were supported in examining and revising otherwise taken-forgranted vocabulary and routine behavior with patients. Transformative outcomes included new perspectives on nursing care goals with chronic obstructive pulmonary disease patients. These were associated with significantly improved 
caring experiences at the affective level ("pleasure versus pressure") for the practitioners. Positive changes in views of the patients themselves also resulted from the training. Finally, an extraordinary shift occurred: nurse trainees described evolving from a stance of silent observation and unilateral decision making on care toward one founded on sharing professional observations, thoughts, and concerns with patients and involving them in the clinical assessment of their situation. They moved from "nursing project" to "joint venture" in the context of personal body care assistance. This became a source of professional pride. New vocabulary (eg, "common agenda") and views on communication (ie, what it really means to listen authentically) also resulted from the training. Furthermore, although the training incorporated the use of tools (eg, an "agreement sheet"), these were embedded into the training program but played a secondary role to the reflection processes.

Awareness of self and critical reflection on practice equally took place through role-play and discussion exercises in other educational programs. ${ }^{31,65}$ For instance, first-year medical students having participated in "patient-centered tobacco intervention" training manifested less judgment toward nonadherent patients; they also developed more favorable attitudes toward physicians' roles in promoting behavioral change. The authors associated these positive attitudinal shifts with the introspective learning activities on students' own process of changing unhealthy behaviors. ${ }^{31}$ Another study used role-play exercises based on actual patient scenarios with maternity ward nursing students. ${ }^{65}$ These fostered awareness of how patients reveal issues in response to nursing approaches. They also learned how "knowing the patient and knowing the person" refer to different types of knowledge.

\section{Alternate ways of knowing}

Education that explicitly fosters reflection on practice and the development of self-awareness constitutes powerful approaches to teaching PCC. The previous section described education that privileged reflective activities in direct relation to practice (ie, through taped recordings of patient-professional interactions or their re-enactment through role-play). In this section, we draw attention to approaches that incorporate what we call "alternate ways of knowing." Here, we refer to teaching modes that depart from traditional practice-based learning and that also contrast with factual and technical/ instrumental learning. By appealing to the senses (eg, aesthetic, ethical, moral) and feelings (eg, sadness, fear, hope, indignation), they aim to assist the student or practitioner in integrating evidence-based knowledge with the complexity and meaning of the illness experience. ${ }^{68}$ Although the health professional education literature is replete with references to the use of art, literature, legal case studies, drama, poems, metaphors, etc, here we discuss two approaches for which a knowledge base - in relation to PCC - is accumulating: (1) use of patient narratives and (2) promoting direct interaction with the "person behind the patient."

\section{Use of patient narratives}

We have argued the importance of shared epistemologies for PCC. This includes the idea that the patient's experience and thoughts on disease and illness are of equal importance to biomedical knowledge for a complete understanding of care needs. It follows that accessing these experiences and perspectives are essential curricular components. Patient narratives may be powerful mediators. ${ }^{34,48,69}$ By offering a glimpse into the subjective experience of illness, narratives provide complementary perspectives and may foster empathy. ${ }^{69}$

In the interprofessional environment characteristic of rehabilitation care, patient narratives proved highly effective in bringing about transformation in staff. ${ }^{48}$ Using qualitative interview data collected with patients and families, Blickem and Priyadharshini ${ }^{48}$ constructed first-person narratives on which to found a continuing education course on PCC. Through critical analysis and discussion of the patient/carer narratives, professionals gained insight into the formerly taken-for-granted privilege of medical and institutional power; they developed awareness of how they themselves were positioned in relation to the medical-institutional discourse and how this can negatively affect patients and families. These realizations prompted discussions about the possibilities for improving patient-professional relationships. The authors demonstrated the value of partly fictionalized and anonymous patient accounts for allowing the participants the distance necessary for critical reflection. They also describe how the narratives allowed the professional to see themselves through the eyes of patient/carers, which in turn helped them see themselves in the narratives of other patients they had cared for. ${ }^{48}$

Similarly, undergraduate medical students gained perspectives on the lived experience of diabetes through contact with personal narratives. ${ }^{34}$ Students accessed stories through conversations with people with diabetes, in their homes and outside the care environment. These conversations took place over the course of 2 years. The students also discussed and reflected on these stories in small groups led by teachers. The students' understanding of diabetes and its management 
significantly expanded, allowing them to "make diabetes personal." ${ }^{34}$ Through the attitudes, feelings, perspectives, and approaches of persons with diabetes, the students' perceptions of life with chronic disease became "individualized." They also gained awareness of the influence of social factors and put into perspective their biomedical knowledge about the disease. Finally, their assumptions about patient goals were challenged, as were their views on doctors' authority. The authors observed that contact with patient and family narratives coupled with direct interaction and observation of the impact of diabetes on their lives stimulated learning in affective, as well as cognitive, dimensions.

\section{Promoting direct interaction with the "person behind the patient"}

As just seen, direct interaction - outside the focus of professional care - with people experiencing disease can provide invaluable learning of its individualized and contextualized nature. This is congruent with the "patient-as-person" dimension of PCC described by Mead and Bower. ${ }^{3}$ Whether framed through a focus on narrative or not, direct interaction aimed at getting to know the person is frequently promoted as an educational approach for developing patient centeredness.

Planning for informal moments of contact with patients (eg, interacting over lunch, bedside conversations), in addition to standard lectures on symptom management and multidisciplinary team functioning, was the main focus of improvements made to a palliative care placement. ${ }^{70}$ The changes proved effective in increasing students' appreciation of the placement. In addition to gaining new understandings about patients' experiences, they reported feeling better connected to them, and even felt a sense of usefulness. ${ }^{70}$ Moments and spaces for "human-to-human" contact were contrasted with "illness-treatment" interactions by the authors.

Providing opportunity for nonprofessional interactions between students and people experiencing illness or dysfunction is also one of the aims of experiential service learning in the health professions. This component has recently been explicitly linked to the promotion and development of PCC. ${ }^{35,36,71}$ Coupled with reflective activities (eg, role-play and journal-keeping), an interdisciplinary service-learning project developed positive attitudes on the part of students toward seniors' desire and capacity for self-sufficiency. ${ }^{71}$ Physiotherapy students improved their understanding of "life with a disability" and its impact on various spheres (eg, work) during their involvement with community volunteers. ${ }^{36}$ In yet another study, dentistry students gained insight into the lives of individuals they normally would not encounter on a daily basis (eg, homeless people); physiotherapy students involved in a parallel project discussed raised awareness of psychosocial issues and access-to-care barriers for people with disabilities. ${ }^{35}$ However, with both these groups, the educational experience appeared to foster PCC characteristics mostly in students already possessing inherent humanistic qualities (ie, empathic and caring) and reflective ability. Some students reported initial feelings of unease and discomfort and course attrition rate was high. The authors emphasized the importance of providing additional mentorship and support to develop reflection in students perceived to need this more. ${ }^{35}$

Finally, the rehabilitation literature provides an example of a training innovation that uniquely taps into the benefits of learning through direct interaction with people living with disease: use of patient instructors. In a 3 hour class for physical and occupational therapy students, certified patient instructors teach joint examination and respectful patient contact. ${ }^{46}$ Working collaboratively with students through dialogue, the instructors address issues related to approaching the patient with rheumatoid arthritis. They are not involved in evaluating the students. Focus groups with students participating in this course revealed their appreciation for the authenticity and intimacy of the sessions. ${ }^{46}$ They also described a sense of safety and openness in this learning environment. When contrasting their experience with clerkship learning, participants related how being free of the "professional" role and responsibility legitimized their learning within the patient-instructor-student relationship. The authors discuss authority and power relations in the traditional educational context and highlight the "clash between students' fulfillment of their learning task and the task of professional identity formation." 46

\section{Toward a transformative learning theory foundation for developing PCC}

We have provided examples of educational approaches in which students or health professionals questioned their roles and position within the care process, revised their perceptions and judgments of patients, gained new perspectives on health and care processes, as well as the contributions of patients to these. Through meaningful and critical reflection, a supportive social learning environment, and access to patients' experiential knowledge, learners' awareness and conception of patient centeredness were touched upon. Comfort with and appreciation for interactions with patients also frequently increased. Finally, ways of relating and caring evolved as a 
result of some of the educational experiences. Although the theoretical foundations in the articles reviewed are most frequently not explicit, an implicit attention is paid to students and practitioners as unique and developing individuals. This is coherent with a developmental framework to learning, and consistent with the psychological and philosophical foundations of adult transformative learning theory. ${ }^{72}$

Among possible adult learning theories, transformative learning stands out because it is intended to provide an educational experience consistent with the purpose of changing acculturated perspectives and behaviors. ${ }^{6,72-79}$ Transformative learning provides the opportunity to confront and engage in critical reflection about the professional's impact on the patient/ family by using their narrative accounts to explore new meanings, roles, relationships, and actions..$^{6,76,78}$ In the classroom, patient/family narratives (or actual patients) are used to engage health professional students, in order to disrupt their habitual perspectives via skillful transformational facilitation processes, which include supported critical questioning and reflection. ${ }^{73}$

Transformational learning aspires to enhance our capacity or repertoire of how we respond to particular situations, requiring us to relearn skills in listening to and interpreting the narratives as more than just factual accounts. ${ }^{7,80}$ The process of transformational learning essentially involves learning how to change one's interpretation of a situation through an active and experiential interaction among the participants and facilitators. ${ }^{72,79}$

In summary, the affective, social, cognitive, and cultural components of the learning process are simultaneously addressed in transformative learning. The readiness to seek out, apprehend, and apply new knowledge is triggered by what transformative learning theorists call a "disorienting dilemma," 72 a sense of disequilibrium or dissonance between acculturated perspectives and those conveyed through patients' stories and reactions. This affective learning moment moves individuals (in this case, the trainees) from experiencing knowledge as a series of facts disconnected from their meaning and context to encountering knowledge as situated, contextualized, and particularly meaningful. ${ }^{72,75}$ New understanding requires that learners assess the meanings behind words, the coherence, truth, and appropriateness of what is being communicated, as well as the truthfulness, credibility, authenticity, and expressiveness of the presenter. Unlike instrumental learning, in which logical problem solving and inquiry dominate, transformative learning entails the use of metaphor, analogies, and reflective dialogue that incite learners to question and revise their interpretations of knowledge. ${ }^{72,74}$ The health care trainee can change her or his frame of reference and perceptions, ultimately, to accommodate new and different ways of learning and engaging with the patient/family, as well as within an interdisciplinary team. ${ }^{76}$

Transformative learning, as an educational framework, equally requires a reconceptualization of the student-teacher relationship. ${ }^{73}$ Moving from directive "expert" to supportive "coach," the trainer seeks to establish with students a relationship of trust and support, both intellectual and emotional; learners are thus better able to "live with the discomfort", associated with critical reflection. ${ }^{72,81,82}$ The importance of a "safe learning environment" is emphasized in recent literature in health professional education concerned with promoting reflection. ${ }^{83}$ These educational dimensions were also evident in many of the studies reviewed in this paper. Advancing academic cultural shifts toward PCC has, in fact, been achieved in some cases through transforming institutional processes (ie, curricular planning/development and assessment) into ones that parallel, model, and value the relationship-centered characteristics of respectful and reflective dialogue among faculty, staff, and students. ${ }^{57}$ These institutional changes have been posited as key in overcoming hidden curricula. ${ }^{57}$ If PCC is to fulfill its mission in constituting a counterbalance to EBM, indeed, our proposed philosophical/epistemological shift must be embraced by and embodied within entire learning environments.

Since PCC learning contexts and content are relevant for faculty, students, and care providers, as well as for patients and families themselves, we posit that adult transformative learning theory provides a common neutral ground from which everyone can learn from each other. Developing patient centeredness is not merely an application of an appropriate pedagogy, but rather demands a significant transformation of academic, professional, and personal perspective about what is and how one becomes patient-, and fundamentally, relationship-centered. Other instructional methods may show what it might or should be like, but provide limited opportunity to engage the learner in formulating a PCC attitude or to transform experienced care providers into authentically patient-centered individuals. The deep and rich scholarship found in decades of learning how to effect change in adults provides an ideal framework for health professional educators and academics to lead the way.

\section{Acknowledgments}

MC Lévesque acknowledges the financial support provided by the following funding agencies and organizations: the Fonds de recherche en santé du Québec (FRSQ), the Network 
for Oral and Bone Health Research (RSBO), and the Centre de recherche de Montréal sur les inégalités sociales et les discriminations (CREMIS).

\section{Disclosure}

The authors report no conflicts of interest in this work.

\section{References}

1. Berwick DM. What 'patient-centered' should mean: confessions of an extremist. Health Aff (Millwood). 2009;28(4):w555-W565.

2. Stewart M, Brown JB, Weston WW, et al. Patient-Centered Medicine, Transforming the Clinical Method, 2nd ed. Abington, UK: Radcliffe Medical Press Ltd; 2003.

3. Mead N, Bower P. Patient-centredness: a conceptual framework and review of the empirical literature. Soc Sci Med. 2000;51(7):1087-1110.

4. Gadamer HG. The Enigma of Health: The Art of Healing in a Scientific Age. Chapter 8, 103-116. Translated by Gaiger J, Walker N, trans. Palo Alto, CA: Stanford University Press; 1996.

5. Gray GR. Teaching patient-centered care. Fam Med. 2002;34(9): 644-645.

6. Hovey R, Cuthbertson K, Birnie K, et al. The influence of distress on knowledge transfer for men newly diagnosed with prostate cancer. J Cancer Educ. 2012;27(3):540-545.

7. Campinha-Bacote J. Delivering patient-centered care in the midst of a cultural conflict: the role of cultural competence. Online J Issues Nurs. 2011;16(2):5.

8. Silow-Carroll S, Alteras T, Stepnick L. Patient-Centered Care for Underserved Populations: Definition and Best Practices. Washington DC: Economic and Social Research Institute; 2006.

9. Bower DJ, Young S, Larson G, et al. Characteristics of patient encounters that challenge medical students' provision of patient-centered care. Acad Med. 2009;84(Suppl 10):S74-S78.

10. Institute of Medicine. Crossing the Quality Chasm: A New Health System for the 21st Century. Washington, DC: The National Academies Press; 2001.

11. Da Silva D. Helping People Share Decision Making: A Review of evidence Considering Whether Shared Decision Making Is Worthwhile. London: The Health Foundation; 2012.

12. Stewart M, Brown JB, Donner A, et al. The impact of patient-centered care on outcomes. J Fam Pract. 2000;49(9):796-804.

13. Record JD, Rand C, Christmas C, et al. Reducing heart failure readmissions by teaching patient-centered care to internal medicine residents. Arch Intern Med. 2011;171(9):858-859.

14. Irwin RS, Richardson ND. Patient-focused care: using the right tools. Chest. 2006;130(Suppl 1):73S-82S

15. Hovey RB, Dvorak ML, Burton T, et al. Patient safety: a consumer's perspective. Qual Health Res. 2011;21(5):662-672.

16. Hughes RG. Overview and summary: patient-centered care: challenges and rewards. Online J Issues Nurs. 2011;16(2)

17. Pelzang R. Time to learn: understanding patient-centred care. Br J Nurs. 2010;19(14):912-917.

18. Lewis S. Patient-Centered Care: An Introduction to What it is and How to Achieve it. Discussion Paper. Regina: Saskatchewan Ministry of Health; 2009.

19. Guba E, Lincoln YS. Fourth Generation Evaluation. Newbury Park, CA: Sage Publications; 1989.

20. Vegni E, Martinoli M, Moja EA. Improving patient-centred medicine: a preliminary experience for teaching communication skills to Italian general practitioners. Educ Health (Abingdon). 2002;15(1):51-57.

21. Sheldon LK. An evidence-based communication skills training programme for oncology nurses improves patient-centred communication, enhancing empathy, reassurance and discussion of psychosocial needs. Evid Based Nurs. 2011;14(3):87-88.
22. Bombeke K, Van Roosbroeck S, De Winter B, et al. Medical students trained in communication skills show a decline in patient-centred attitudes: an observational study comparing two cohorts during clinical clerkships. Patient Educ Couns. 2011;84(3):310-318.

23. Smith RC, Marshall-Dorsey AA, Osborn GG, et al. Evidence-based guidelines for teaching patient-centered interviewing. Patient Educ Couns. 2000;39(1):27-36.

24. Bombeke K, Symons L, Vermeire E, et al. Patient-centredness from education to practice: the 'lived' impact of communication skills training. Med Teach. 2012;34(5):e338-e348.

25. Haidet P, Teal C, Shada R, Huang W, Scott S, Thompson B. Following the clues: A curriculum to help students understand patient-centered information. Abstract of the 33rd Annual Meeting of the Society of General Internal Medicine; April 28-May 1, 2010; Minneapolis, MN. Journal of General Internal Medicine. 25(3 Supp): 279-280.

26. McKeon LM, Norris T, Cardell B, Britt T. Developing patient-centered care competencies among prelicensure nursing students using simulation. J Nurs Educ. 2009;48(12):711-715.

27. Haidet P, Dains JE, Paterniti DA, Chang T, Tseng E, Rogers JC. Medical students' attitudes toward patient-centered care and standardized patients' perceptions of humanism: a link between attitudes and outcomes. Acad Med. 2001;76(Suppl 10):S42-S44.

28. Smith SR, Cookson J, Mckendree J, et al. Patient-centred learning back to the future. Medical Teacher. 2007;29:33-37.

29. Claramita M, Sutomo AH, Graber MA, Scherpbier AJ. Are patientcentered care values as reflected in teaching scenarios really being taught when implemented by teaching faculty? A discourse analysis on an Indonesian medical school's curriculum. Asia Pacific Fam Med. 2011;10(1):4.

30. Richards PS, Inglehart MR. An interdisciplinary approach to casebased teaching: does it create patient-centered and culturally sensitive providers? J Dent Educ. 2006;70(3):283-291.

31. Brown RL, Pfeifer JM, Gjerde CL, Seibert CS, Haq CL. Teaching patient-centered tobacco intervention to first-year medical students. J Gen Intern Med. 2004;19(5 Pt 2):534-539.

32. Ross EF, Haidet P. Attitudes of physical therapy students toward patientcentered care, before and after a course in psychosocial aspects of care. Patient Educ Couns. 2011;85(3):529-532.

33. Thistlethwaite JE. Introducing medical students to the concept of patient-centred consultations during a community-based teaching attachment. Medical Teacher. 1999;21(5):523-526.

34. Kumagai AK, Murphy EA, Ross PT. Diabetes stories: use of patient narratives of diabetes to teach patient-centered care. Adv Health Sci Educ Theory Pract. 2009;14(3):315-326.

35. Roskell C, White D, Bonner C. Developing patient-centred care in health professionals: reflections on introducing service-learning into the curriculum. Int J Ther Rehabil. 2012;19(8):448-456.

36. Rapport MJ, Rodriguez J, Bade M. Use of a community volunteer program to develop value for patient-centered care in physical therapist professional education. Journal of Physical Therapy Education. 2010;24(2).

37. Ruston A, Tavabie A. An evaluation of a training placement in general practice for paramedic practitioner students: improving patient-centred care through greater interprofessional understanding and supporting the development of autonomous practitioners. Qual Prim Care. 2011;19(3): $167-173$.

38. Staun M, Bergström B, Wadensten B. Evaluation of a PBL strategy in clinical supervision of nursing students: patient-centred training in student-dedicated treatment rooms. Nurse Educ Today. 2010;30(7): 631-637.

39. Krupat E, Pelletier S, Alexander EK, Hirsh D, Oqur B, Schwartzstein R. Can changes in the principal clinical year prevent the erosion of students' patient-centered beliefs? Acad Med. 2009;84(5):582-586.

40. Morris J, Leonard R. Physiotherapy students' experiences of palliative care placements - promoting interprofessional learning and patientcentred approaches. J Interprof Care. 2007;21(5):569-571. 
41. Howe A. Patient-centred medicine through student-centred teaching: a student perspective on the key impacts of community-based learning in undergraduate medical education. Med Educ. 2001;35(7):666-672.

42. Thistlethwaite JE, Jordan JJ. Patient-centred consultations: a comparison of student experience and understanding in two clinical environments. Med Educ. 1999;33(9):678-685.

43. Lomborg K, Nielsen ES, Jensen AL, Jørgsensen LB. Achieving competences in patient-centred care: an evaluation study of a training programme in assisted personal body care for respiratory patients. Journal of Nursing and Healthcare of Chronic Illness. 2011;3(3): 265-274.

44. Davis P, Clackson J, Henry C, Bobyn J, Suveges L. Interprofessional continuing health education for diabetic patients in an urban underserved community. J Interprof Care. 2008;22 Suppl 1:51-60.

45. Schoot T, Hirsch M, De Witte L. Development of competencies aimed at client-centred care: an evaluation study. Learning in Health and Social Care. 2007;6(2):104-117.

46. Henriksen AH, Ringsted C. Learning from patients: students' perceptions of patient-instructors. Med Educ. 2011;45(9):913-919.

47. Tripicchio B, Bykerk K, Wegner C, et al. Increasing patient participation: the effects of training physical and occupational therapists to involve geriatric patients in the concerns-clarification and goal-setting processes. Journal of Physical Therapy Education. 2009;23(1):55-63.

48. Blickem C, Priyadharshini E. Patient narratives: the potential for "patientcentred" interprofessional learning? J Interprof Care. 2007;21(6): 619-632.

49. Hojat M, Vergare, MJ, Maxwell K, et al. The devil is in the third year: a longitudinal study of erosion of empathy in medical school. Acad Med. 2009;84(9):1182-1191.

50. Tsimtsiou Z, Kerasidou O, Efstathiou N, Papaharitou S, Hatzimouratidis K, Hatzichristou D. Medical students' attitudes toward patient-centred care: a longitudinal survey. Med Educ. 2007;41(2):146-153.

51. Bosma H, Diederiks J, Scherpbier A, Van Eijk J. A gender-specific evaluation of a care-oriented curricular change in a Dutch medical school. Med Teach. 2010;32(1):e18-e23.

52. Trotter DR, Evans L, Jones BG, et al. Is it possible to sustain a halt in the decline of medical students' patient-centered beliefs? Fam Med 2010;42(9):657-658.

53. Bombeke K, Symons L, Debaene L, De Winter B, Schol S, Van Royen P. Help, I'm losing my patient-centredness! Experiences of medical students and their teachers. Med Educ. 2010;44(7):662-673.

54. Ribeiro MM, Krupat E, Amaral CF. Brazilian medical students' attitudes towards patient-centered care. Med Teach. 2007;29(6):e204-e208.

55. Wahlqvist M, Gunnarsson RK, Dahlgren G, Nordgren S. Patient-centred attitudes among medical students: gender and work experience in health care make a difference. Med Teach. 2010;32(4):e191-e198.

56. Madhan B, Rajpurohit AS, Gayathri H. Attitudes of postgraduate orthodontic students in India towards patient-centered care. J Dent Educ. 2011;75(1):107-114.

57. Christianson CE, McBride RB, Vari RC, Olson L, Wilson HD. From traditional to patient-centered learning: curriculum change as an intervention for changing institutional culture and promoting professionalism in undergraduate medical education. Acad Med. 2007;82(11):1079-1088.

58. Skaalvik MW, Normann HK, Henriksen N. Student experiences in learning person-centred care of patients with Alzheimer's disease as perceived by nursing students and supervising nurses. J Clin Nurs. 2010;19(17-18): 2639-2648.

59. McCarthy B. Translating person-centred care: a case study of preceptor nurses and their teaching practices in acute care areas. J Clin Nursing 2006;15(5):629-638

60. Roskell C. Patient-centred practice in physiotherapy: linking professional identity and learning. Int J Ther Rehabil. 2009;16(5):246-247.

61. Pegon-Machat E, Tubert-Jeannin S, Loignon C, Landry A, Bedos C. Dentists' experiences with low-income patients benefiting from a public insurance program. Eur J Oral Sci. 2009;117(4):398-406.
62. Weiss MC, Peters TJ. Measuring shared decision making in the consultation: a comparison of the OPTION and Informed Decision Making instruments. Patient Educ Couns. 2008;70(1):79-86.

63. Eriksen HM, Bergdahl J, Bergdahl M. A patient-centred approach to teaching and learning in dental student clinical practice. Eur J Dent Educ. 2008;12(3):170-175.

64. Grosch K, Medvene L, Wolcott H. Person-centered caregiving instruction for geriatric nursing assistant students: development and evaluation. J Gerontol Nurs. 2008;34(8):23-31.

65. Storr GB. Learning how to effectively connect with patients through low-tech simulation scenarios. International Journal for Human Caring. 2010;14(2):36-40.

66. Smith RC, Dorsey AM, Lyles JS, Frankel RM. Teaching self-awareness enhances learning about patient-centered interviewing. Acad Mede. 1999;74(11):1242-1248.

67. Bergvik S, Wynn R, Sørlie T. Nurse training of a patient-centered information procedure for CABG patients. Patient Educ Couns. 2008;70(2):227-233.

68. Smith-Stoner M. Teaching Patient-Centered Care During the Silver Hour. Online J Issues Nurs. 2011;16(2):6.

69. Kumagai AK. A conceptual framework for the use of illness narratives in medical education. Acad Med. 2008;83(7):653-658.

70. Linklater G. Promoting patient-centredness in undergraduate palliative care education. Med Educ. 2008;42(11):1126-1127.

71. Dacey M, Murphy JI, Anderson DC, McCloskey WW. An interprofessional service-learning course: uniting students across educational levels and promoting patient-centered care. J Nurs Educ. 2010;49(12):696-699.

72. Mezirow J. Transformative Dimensions of Adult Learning. San Francisco, CA: Jossey-Bass, Inc; 1991:33.

73. Cranton P. Understanding and Promoting Transformative Learning, A Guide for Educators of Adults. San Francisco: Jossey-Bass Publishers; 1994.

74. Merriam S, Caffarella R, Baumgartner L. Learning in Adulthood: A Comprehensive Guide, 3rd ed. San Francisco: John Wiley \& Son; 2007.

75. McWilliam CL. Continuing education at the cutting edge: promoting transformative knowledge translation. J Contin Educ Health Prof. 2007;27(2):72-79.

76. Hovey R, Craig R. Understanding the relational aspects of learning with, from, and about the other. Nurs Philos. 2011;12(4):262-270.

77. Hovey R, Massfeller H. Exploring the relational aspects of patient and doctor communication. $J$ Med Pers. 2012;10(2):81-86. DOI 10.1007/ s12682-012-0123-0

78. Hovey R. Assessment in health promotion: deconstruction and metaphoric considerations in a nutshell. In: Gilmore GD, editor. Needs and Capacity Assessment Strategies for Health Education and Health Promotion, 4th ed. Sudbury, MA: Jones and Bartlett, LLC; 2012.

79. Phillipi J. Transformative learning in healthcare. PAACE Journal of Lifelong Learning. 2010;19:39-54.

80. Davey N. Unquiet Understanding: Gadamer's Philosophical Hermeneutics. Albany, NY: State University of New York Press; 2006.

81. Taylor EW. An update of transformative learning theory: a critical review of the empirical research (1999-2005). International Journal of Lifelong Education. 2007;26(2):173-191.

82. Boler M, Zembylas, M. Discomforting Truths: The Emotional Terrain of Understanding Differences. In: Tryfonas P, editor. Pedagogies of Differences: Rethinking Education for Social Justice. New York Routledge; 2003:110-136.

83. Mann K, Gordon J, MacLeod A. Reflection and reflective practice in health professions education: a systematic review. Adv Health Sci Educ Theory Pract. 2009;14(4):595-621. 
Journal of Healthcare Leadership

Dovepress

\section{Publish your work in this journal}

The Journal of Healthcare Leadership is an international, peer-reviewed, open access journal focusing on leadership for the health profession. The journal is committed to the rapid publication of research focusing on but not limited to:

Healthcare policy and law; Theoretical and practical aspects healthcare delivery; Interactions between healthcare and society and evidence-based practices;

Interdisciplinary decision-making; Philosophical and ethical issues; Hazard management; Research and opinion for health leadership; Leadership assessment. The manuscript management system is completely online and includes a very quick and fair peer-review system. Visit http://www.dovepress.com/ testimonials.php to read real quotes from published authors.

Submit your manuscript here: http://www.dovepress.com/journal-of-healthcare-leadership-journal 